\title{
Government libraries and official publications management: all we need is a repository model
}

\author{
Lucia Antonelli ${ }^{1}$
}

Library of the Central Directorate for Autonomies. National register of municipal clerks, Ministry of the Interior, Rome, Italy

\begin{abstract}
Ministries and public bodies produce many different types of documents, largely in digital format: monographs, reports, studies, researches, journals, statistical data collections, teaching materials, regulatory dossiers, bibliographic collections and more. It is a documentary strand represented by a particular typology of grey literature, often organized by government libraries. These documents, generally open by default, are produced and financed by public funds and are intended for citizens, administrations, associations and others. For this reason, online retrieval of official publications must be always guaranteed in terms of accessibility, reliability, updating, persistence over time. The most appropriate tool for an effective management of official publications of a public body is an open access document repository, that is to say a collection of digital resources accompanied by descriptive, structural and administrative metadata. Therefore, a repository model is proposed and its functional and structural requirements as well as technological-formal features, are defined and identified in detail.
\end{abstract}

\section{Introduction: Government Libraries and official publications}

According to the Guidelines for Libraries of Government Departments of the International Federation of Library Association, government libraries can be divided into three categories: Libraries of the Legislature, Libraries of the Executive, Libraries of the Judiciary. Within the respective institutions, government libraries support their objectives, making available all types of published information, helping the formulation of programs and policies, administrative and regulatory actions, consultancy functions and research programs [1].

In any country government libraries preserve, catalogue and make available to users a rich and heterogeneous amount of documents and resources: books, magazines, databases and much more. Government libraries also collect and organize official publications produced within the institution to which they belong and this peculiar aspect defines one of their traditionally characterizing functions.

1 lu.antonelli@libero.it 
Starting from these premises, this work analyzes the tools that can be effectively adopted by government libraries for the online management of official publications they deal with. The impact deriving from an adequate management of these documents represent a tangible contribution to the implementation of open government, transparency and participative democracy, as well as the dissemination of knowledge tout court.

In the first part, the analysis here presented is focused on the Italian framework of public documents produced by administrative bodies. After a brief and preliminary review dedicated to the various types of public documents available online, particular attention is paid to official publications and their critical aspects in terms of retrieval via the web [2]. Although the critical issues highlighted concern the Italian context, it is not excluded that the solutions proposed may, in some cases, be taken as a reference by other countries too. In the second part of this work, the analysis focuses on the tools available to libraries for effective management of official publications: the so-called "repositories", for which a structural model is offered through a description of its basic functional requirements and its technological-formal features as well.

\section{Public documents}

Public documents consist of data, documents and information produced by public bodies in the exercise of their various institutional and administrative activities. Documents of such stuff are various and different, both in terms of typology and purpose. On the one hand there are legislative acts, sentences, ordinances, resolutions, directives, executive decisions, municipal resolutions and much more: in short, a type of documents without which public administrations would not see their own activities exist. And on the other hand, public documents defined as "official publications" [3] such as reports, studies, researches, periodical publications, guidelines, statistical collections, bulletins, dossiers, annual reports: documents that summarize and illustrate the themes of interest of an institution from a disciplinary point of view.

Public documents, currently produced by ministries and public bodies, largely only in digital format by now, are generally open by default, they are produced and financed by public funds and they are intended for citizens, administrations, associations and others. For this reason, their online retrieval must be guaranteed as much as possible in terms of accessibility, reliability, updating and persistence over time.

Public documents are therefore a very large and composite corpus that represents a precious resource regarding multiple aspects: administrative-managerial, political-economic and, last but not least, socio-cultural.

\section{Official publications online management: the case of Italy}

Among the many categories of public documents, an important place is occupied by "official publications": monographs, periodicals, reports and more are in fact traditionally produced by public institutions of all kinds in the exercise of their activity. In many cases, these are documents that traditionally can be included among in what is called "grey literature", that is documents disseminated outside the usual commercial publishing circuits and produced within public or private organizations or institutions of any sector and discipline [4].

Official publications must be adequately valued and disseminated, thus contributing to extending the availability of public information assets within the social context to which they belong. In Italy, with regard to the dissemination and the online availability of these types of documents, generally there is one main way to manage and, consequently, retrieve them. It consists in using a specific section of the website where, defined under the label of 
"publications", in these sections documents can be collected and listed by chronologically or semantic criteria and the full-text availability is not always guaranteed. In this way, the official publications retrieval can be difficult, due to many factors: the variety and richness of this kind of documents, the obsolescence of some websites, the lack of standardization in terms of description, the document dispersion and fragmentation among the websites.

Therefore, a paradigm shift is needed. More articulated research methods should be envisaged and allowed, abandoning the common practice of presenting web pages with simple lists of editorial products of a public body.

\section{The Repositories: open archives for the management of official publication}

For the management of official publications in Italy, it would be desirable to have specific databases, the so-called "repositories"[5], that is to say a collection of digital resources accompanied by descriptive, structural and administrative metadata [6-7] supported by specific and effective management systems. Repositories are tools that make it possible to organize publications in a real catalog, facilitating their search and full-text retrieval on line as well.

In many cases repositories of documents are also known as "open archives", sophisticated document management tools that have spread internationally and also in Italy over the last fifteen to twenty years. These are digital document deposits mainly used in the academic field and which contain articles, studies, handouts or research produced within an institution or within a disciplinary sector. They are called "open" as they make it freely accessible to all documents catalogued online. Furthermore, from a technical point of view, they are supported by $\mathrm{s} / \mathrm{w}$ open source and are interoperable with other related systems based on internationally shared standards and based on metadata descriptive used for identification and retrieval of documents. Academic open archives are part of the international movement of the Open Access Initiative (OAI), by virtue of which free online access is allowed to the documentation produced by a specific institution thanks to public funding [8].

Due to the characteristics just described, the open archives can therefore also be used by government bodies for the management of digital books, journals, studies, researches, reports, monographs and other documents produced. And for doing this, is relevant the role of librarians who work in government libraries. In support of a vision of libraries that can perform a basic function in the conservation, cataloging and dissemination of official publishing through open institutional archives, there are international studies, among which that of Wendy Pradt Lougee, which refers to the role of librarians in the production of scientific research and which is also well suited to the context of public documents; the author herself states that in the library the functions of content management, archiving and dissemination coexist [9].

So, repositories are a positive and effective choice to manage official publications and it seems appropriate to hope that they will also be used by public administrations for the management of their own publishing products. In this way there would be multiple and shared benefits: for institutions because they would see their publishing production greatly enhanced and more widespread, for citizens because they could access documents more easily, for government libraries because they would see an increase in supply of the documentary heritage available to real and potential users, for librarians because they would acquire new skills and improve the offer of information services in terms of effectiveness and updating. 


\section{Repository Model for official publications}

An institutional repository model is therefore proposed, aimed at the online management of digital official publications created by an institution or a public body. The model presented does not provide a rigid and fixed structure, which would be difficult to share and apply in general terms; rather, it offers a neutral and scalable basic scheme which can prove useful for the starting configuration for the design of activities related to the creation of repositories for official publications.

From a technical and formal point of view, for a repository the following are fundamental: compliance with standards, use of shared metadata, interoperability, long-term preservation, accessibility, the effectiveness of the search and retrieval of documents and information relating to them.

The structural model of the institutional repository is illustrated on a synoptic scheme that is divided into the following four areas: Software, Structure, Materials, Policies (Fig. 1). Each area is related to several other sub-topics.

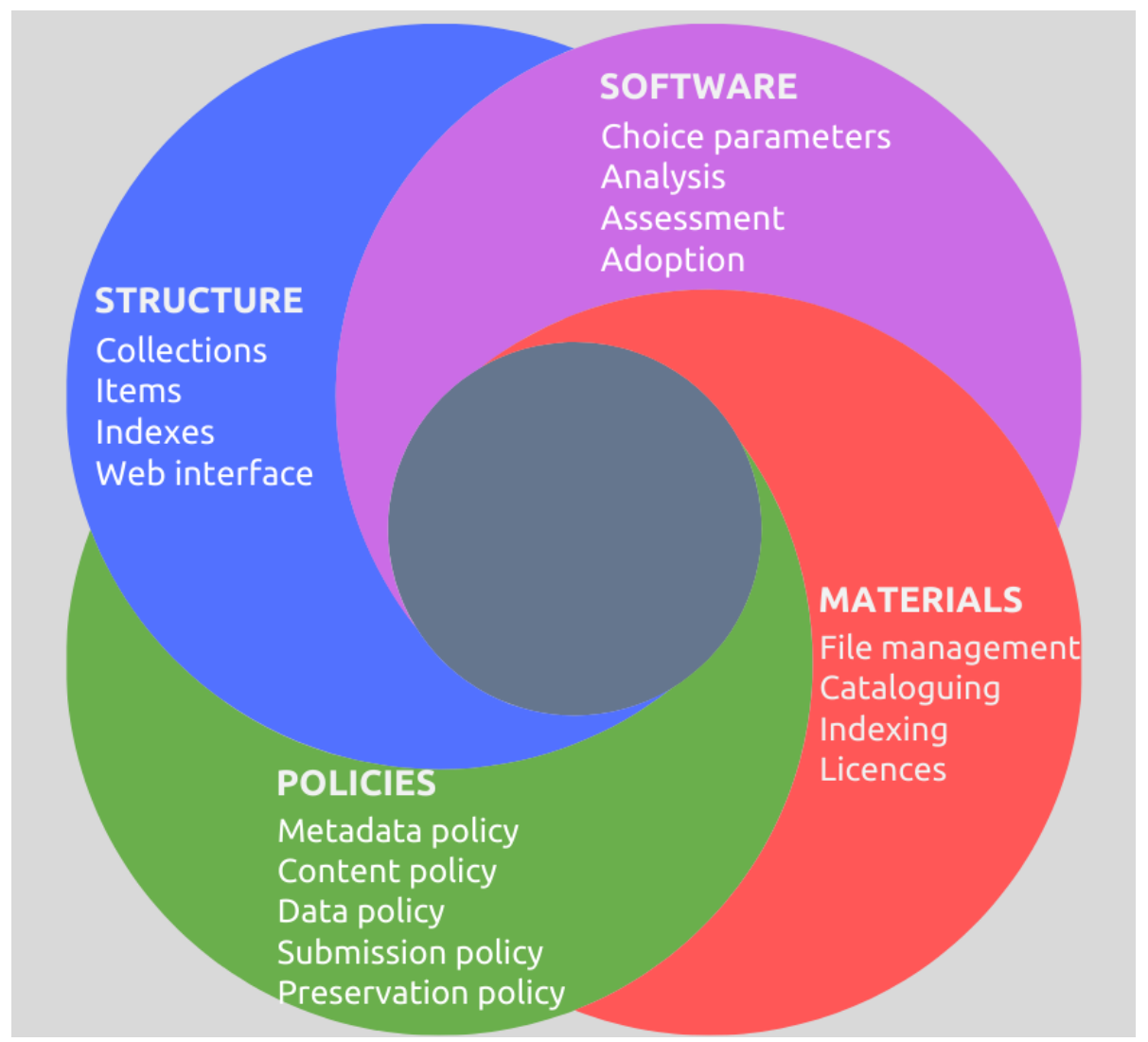

Fig. 1. Repository Model schema.

Each sub-topic listed in the Repository Model schema can be further developed and detailed at different levels, according to the information needs of the repository they relate to. Some of the basic features and functional requirements of a document repository areas sub-topics are set out below. 


\subsection{Structure}

\subsubsection{Collection}

Repositories can be structured mainly according to collections. Therefore, to set up the repository, preliminary configuration activities must be carried out in order to identify collections, sub-collections and their hierarchical structure and naming criteria. It should be possible to add any new collections after the initial configuration. Collections and subcollections names can correspond to departments or offices denominations of the institution to which they belong, otherwise to editorial series of publications produced by the institution or to disciplinary sectors and topics relating to the institution activity. The choice of the criteria for creating and naming the collections depends upon the purposes and of the repository. Each collection can be described with metadata.

\subsubsection{Items}

Items include the documents and the descriptive metadata associated with them. In this model, the Dublin Core (DC) descriptive metadata is adopted. The DC metadata is used to insert the descriptive elements of each record and to set any indexing criteria for searching and retrieving the documents catalogued in the repository. It can be used with the 15 DC basic elements, or the extended version. The 15 basic DC metadata is recommended as minimum requirements to ensure an effective level of description for the purpose of describing and retrieving documents. One or more items that make up the repository can be linked to each collection.

\subsubsection{Indexes}

In a repository, the search for information relating to documents takes place on the basis of two methods: by terms (using the simple and advanced search masks) and by scrolling lists (browsing). These modes are connected with the choice and configuration of the indexing criteria adopted for the repository (author, subject, title, date or other). The navigation indexing criteria provided could be: authority files (document search method based on different access keys), collections, filters, tags.

\subsubsection{Web interface}

To ensure a minimum level of information elements, the home page of the repository must normally include the presence of a header containing the name and logo of the repository, a navigation menu, a text with presentation of the repository, a basic search form and a link to advanced search form. The home page of the repository may also include the presence of new documents or collections.

\subsection{Materials}

\subsubsection{File management}

In creating a repository, specific criteria must be chosen to proceed with the insertion of contents. For example, it can be chosen to upload only the documents of the last five years, or only the monographs and not the periodicals. In any case, the initial criteria set can always be expanded or modified in subsequent phases depending on the priorities and specific needs of the institution or the requests of users. The document selection criteria can be chronological or can depend upon format, topic, type, provenance. All the files that will feed the repository will be gathered, standardized and formatted in advance. 


\subsubsection{Cataloguing and indexing}

Once selected, collected and named, the files are ready to be inserted into the repository. The cataloging of each document is based on a structured metadata set up. Each item will contain both the information provided by the metadata structure and the document file. The description of the documents include the indexing with the link to authority files elements in use.

\subsubsection{License}

In compliance with the principles of open access, documents published in an institutional repository can be assigned specific licenses to share works according to the "some rights reserved" model. Generally The Creative Commons Public Licenses (CCPL) are recommended and the licenced level can be chosen according to the purposes of the repository.

\subsection{Software}

\subsubsection{Choice parameters}

For a repository it is recommended to use a Content Management System for digital archives or institutional repositories. Criteria for choosing the $\mathrm{s} / \mathrm{w}$ will be based on the user license, the server that will host it, the functionality.

\subsubsection{Analysis and assessment}

For the purposes of analyzing the s/w available on the market, preliminary tests could be carried out. The system must be chosen based on the needs of the institution, but it is preferable that it includes the use of Dublin Core descriptive metadata and that it is OAIPMH compliant. The choice of the s/w must also be formulated on the basis of the following characteristics: repository objectives, management, price, responsive web design, integration with semantic web.

\subsubsection{Adoption}

Based on the criteria for adopting the s/w chosen, different activities will be carried out before starting to use the system, which include, at least, activities with offices in charge of information systems management of the institution, operators training with exercises in the test environment, setting up and repository configuration.

\subsection{Policies}

There are of different type of policies to adopt for a repository: Metadata Policy are related to information used to describe items of the repository; Content Policy are related to types of document and data set used; Data Policy indicates criteria for full-text and other full data items, Submission Policy is related to depositors and copyright; Preservation Policy concern accessibility and retained period. Each policy will be detailed on the basis of the choices made by the institution.

\section{Conclusion}

Increasingly widespread use of open access repositories among Italian government libraries would be desirable, especially if related to the adoption of a simple and scalable model handled with an open source content management system. Libraries that provide repositories of digital official publications produced by their institutions can concretely contribute to improving the SSH sector through an appropriate use of information technologies. 
Furthermore, a consolidated use of document repositories by public administrations libraries could contribute to reducing the level of information dispersion of grey literature in general and of public publishing in particular and, in order to support SSH, could help to develop research in legal-administrative disciplines.

Besides, taking into account an open perspective to inter-institutional projects, repositories management could also be addressed through collaborative experiences, perhaps by collecting the documents in databases shared between several public bodies.

In conclusion and from a broader point of view, official publications repositories would implement the transparency levels of public activity in compliance with the principles of open government and for the purposes of accountability with respect to entire citizenship.

\section{References}

1. Bolt, N., Burge, S. (eds.). (2008). Guidelines for Libraries of Government Departments. The Hague: IFLA Headquarters, https://www.ifla.org/files/assets/hq/publications/professional-report/106.pdf

2. Venturini, F. (2018). L'editoria pubblica in rete tra autonomia e controllo: dal feudalesimo alla federazione?. AIB Studi, 58(2), 225-239, https://doi.org/10.2426/aibstudi-11773

3. Johansson, E. A. (1982). The Definition of Official Publications. IFLA Journal, 8(3), 282-290, https://doi.org/10.1177\%2F034003528200800310

4. Farace, D., Schöpfel, J. (2010). Grey Literature in Library and Information Studies, Berlin, New York: K. G. Saur, https://doi.org/10.1515/9783598441493

5. Anderson, B. (2004). Open Access and Institutional Repositories. Behavioral \& Social Sciences Librarian (23)1, 97-101

6. Suber, P. (2012). Open access. Cambridge: MIT Press

7. Jones, C. (2007). Institutional repositories: content and culture in an open access environment. Oxford: Chandos

8. Abadal, E (2014). Open Access: l'accesso aperto alla letteratura scientifica. Milano: Ledizioni

9. Pradt Loungee, W. (2007). La comunicazione scientifica e le biblioteche: le opportunità dei beni comuni, La conoscenza come bene comune. Dalla teoria alla pratica, a cura di Charlotte Hess e Elinor Ostrom, Milano: Mondadori 